\title{
Translanguaging and the No Voice policy in L2 sign language contexts
}

\author{
Josée-Anna Tanner and Nina Doré \\ joseeanna.tanner@carleton.ca \\ CARLETON University
}

\begin{abstract}
This article draws on translanguaging theory and research to consider a common pedagogical practice in American Sign Language (ASL) as a second language (L2) classroom, the No Voice policy (i.e., spoken language use is forbidden). The No Voice policy serves important cultural and practical purposes, but by nature limits learners' access to their entire linguistic repertoire, which raises questions about the overall impact of the policy on learners' language development. Current literature about pedagogical translanguaging has not yet addressed practices that integrate (and, by extension, limit) selective modalities; we evaluate this gap and propose several directions for future research on the topic. Moreover, previous discussions of translanguaging practices involving recognized minority (e.g., Basque, Welsh, Irish) spoken languages are not wholly comparable to sign languages, which are not yet official or fully recognized languages in most countries and are therefore additionally vulnerable. We take into account the impact of ASL L2 learners on the language community, as many learners go on to become interpreters and allies to the deaf community.
\end{abstract}

Key words: American Sign Language as a second language, hearing adult learners, selective modality, pedagogical translanguaging, minority language

\section{Résumé}

Cet article s'appuie sur la théorie et la recherche sur le translanguaging pour envisager une pratique pédagogique commune en langue des signes américaine (ASL) comme langue seconde (L2), dans le cadre de la politique No Voice (où le recours à la langue parlée est interdit). La politique No Voice répond à des objectifs culturels et pratiques importants, mais limite par sa nature l'accès des apprenants à l'ensemble de leur répertoire linguistique, ce qui soulève des questions quant à l'impact global de la politique sur le développement linguistique des apprenants. La littérature actuelle sur le translanguaging à visée pédagogique n'a pas encore 
abordé les pratiques qui intègrent (et, par extension, limitent) des modalités sélectives. Nous évaluons donc cette lacune et proposons plusieurs pistes pour les recherches futures sur le sujet. En outre, les discussions précédentes sur les pratiques du translanguaging impliquant une minorité reconnue (les minorités basque, galloise et irlandaise, par exemple) ne sont pas tout à fait comparables aux langues des signes, car ces dernières ne sont pas encore des langues officielles ou pleinement reconnues dans la plupart des pays et sont donc également vulnérables. Nous prenons en compte l'impact des apprenants en ASL de L2 sur la communauté linguistique, car nombre d'élèves deviennent interprètes et alliés de la communauté des sourds.

Mots-clés : langue des signes américaine comme langue seconde, apprenants adultes entendants, modalité sélective, translanguaging pédagogique, langue minoritaire

\section{Introduction}

American Sign Language (ASL) is the most common sign language used in deaf communities across North America. In the 1980s an increasing number of hearing people began learning ASL as a second language (L2) in secondary and post-secondary settings. In 2015, the Modern Language Association (MLA) reported that ASL displaced German as the additional language with the most enrolments in U.S. high schools and colleges (Goldberg, Looney, \& Lusi, 2015). Canadian figures have not been recorded officially, though Doré $(2014,2016)$ reported that 30 post-secondary institutions in Canada offer ASL, from single continuing education courses to four-year certificates.

Although this expanding group of students is primarily hearing (i.e., have a spoken language as their first language [L1]), their teachers are most often deaf. There is a long history of hearing hegemony that has repeatedly denied sign language rights to deaf people, a fight that continues today, especially for deaf children's rights to a sign language education (see, for example, Komesaroff, 2008; Kuntze, Golos, Wolbers, O’Brian, \& Smith, 2016; Snoddon, 2008). Thus, the popularity of ASL as L2 for a hearing population represents a shift in the language user base and raises complex questions about language growth and ownership alongside questions about the language acquisition needs of these emerging bilingual-bimodal learners.

This article considers a common pedagogical practice in ASL classrooms, the No Voice policy. This policy restricts the use of a dominant language (English) in a dominant mode (spoken) to support the learning of a minority language (ASL) in a minority mode (signed). For context, in ASL classrooms written English is often permissible (e.g., textbooks, chalk-talk, vocabulary lists), but spoken English is usually forbidden. Not voicing is an embedded 
part of ASL communication amongst fluent signers, but maintaining silence is not something that hearing learners do automatically or instinctively; learners need to be consistently reminded to turn off their voices when they enter the classroom. However, restricting the spoken English mode potentially conflicts with the translanguaging goal of encouraging students to access and make use of their entire linguistic repertoire. We explore this paradox throughout the article.

\section{Focus and scope}

Unlike de Saussure's formal language system (2017) or Chomsky's notion of Universal Grammar (1976), translanguaging posits that languages do not exist as separate systems in the brains of language users. García and Wei (2014) argue for a dynamic view of bilingualism where the language practices of bilinguals and emerging bilinguals are drawn from one expanding linguistic system. Bilinguals maximize communicative potential by translanguaging, accessing different features or modes of autonomous languages (García, 2009). Cenoz and Gorter (2017) propose that translanguaging can be promoted through intentional pedagogical decisions and benefit additional language learning by providing a toolkit for accessing the L2. There is thus a theoretical dilemma in ASL as L2: can integrating students' diverse linguistic resources in only one mode (written) still be considered a form of pedagogical translanguaging? Otherwise put, is selective modality pedagogical translanguaging a contradictory term? If it is possible, is it an effective practice in terms of both promoting ASL acquisition and instilling an understanding and respect for deaf social norms?

To consider these questions, we begin by outlining the roles of the No Voice policy as an illustration of how pedagogical translanguaging in the ASL classroom is modality-selective. We then propose three avenues for contextualizing and conceptualizing the impact of this policy on teaching and learning. Firstly, we consider translanguaging research about minority languages, as it provides insight into the potential benefits of the No Voice policy in terms of the minority language status of ASL. We discuss the struggle of ASL to assert itself in the face of spoken English language dominance where limiting English in the classroom can be considered an extension of efforts to reclaim ASL for the deaf community. Secondly, we introduce ASL L2 learners and discuss the No Voice policy in terms of their language acquisition and L2 identity development. This section in particular calls for additional empirical research into the impact of pedagogy on acquisition. Thirdly, in light of the scarcity of literature that discusses the No Voice policy, we consider it conceptually in terms of how it facilitates the different roles that teachers take on in the ASL L2 classroom. We focus on the roles of cultural facilitators, spokespeople for the community, and linguistic experts. All in all, we emphasize the complexity and delicacy 
of this topic and encourage further research, as literature in this area is sorely lacking.

We write from several perspectives which are essential to understanding our scope and approach to the topic. We are both hearing L2 ASL users. We are both involved in sign language communities, but we do not speak as representatives of these communities in any way. We hold that although the spread of ASL as L2 is fraught with real risks to the language and its users, it also provides two important opportunities:

- to develop a wider user base that may bolster the minority language and give it better staying power in the face of ongoing threats (e.g., cochlear implants, ongoing prioritization of the oralist education model)

- encourage a better-informed hearing population whose members may in the future become allies in reducing social (and other) barriers to deaf people.

As researchers, we emphasize the necessity of research-based ASL pedagogy that balances the language acquisition needs of hearing learners with the realworld language concerns of the deaf community.

\section{No Voice policy}

Within the L2 classroom, the No Voice policy plays two key roles. First, it serves the sociocultural purpose of familiarizing students with deaf cultural norms (e.g., how to get someone's attention without voicing). At the same time, the students develop an awareness of their hearing privilege and how to lessen it in signing spaces by making their language accessible to their deaf teachers (i.e., visible, signed), thus showing respect that is anticipated to carry through to their future interactions with deaf people.

Secondly, the No Voice policy immerses students in a visual world, creating a more "authentic" signing context, which is intended to lead to more fluent signers who go on to present a less English-influenced form of ASL. Keeping voicing out of the classroom reduces the likeliness of students developing the habit of using simultaneous communication ("SimCom"; i.e., speaking while signing), which has been shown to be an ineffective communication approach with deaf people (Tevenal \& Villanueva, 2009).

However, there is little evidence that the policy actually results in more proficient signers. In an early ASL L2 study (McKee \& McKee, 1992) students reported that the use of their L1 to explain complicated linguistic concepts resulted in less frustration. These explanations can be done by supplementing ASL explanations with written explanations on the chalkboard or providing pre-prepared handouts - particularly with low-proficiency students. But the No Voice policy would mean that learners could not respond or ask complex 
questions in their L1 (to their instructor or to each other), except in writing. No empirical research has yet addressed how learning is impacted by voicing in the classroom.

\section{ASL as a minority language}

Discussions of ASL pedagogy are preceded by the long history of oppression of sign languages and their users. The displacement of ASL in favour of oralist deaf education meant that the use of ASL by deaf signers was considered shameful, uneducated, or backwards. This history has led to complex power differentials between deaf and hearing people, issues of social capital, and definitions of disability. For many ASL teachers this is their lived history. Allowing only select modalities in the ASL classroom may be an effective tool for creating an alternate discourse. Below we discuss how translanguaging may interfere with the need to protect and maintain ASL and problems arising from its ongoing contact with English.

\section{Protection and maintenance}

As the fight to revitalize the Welsh language during the late 20th century became more successful, the concept of translanguaging emerged out of growing evidence that using two languages for learning can be "mutually advantageous in a bilingual school, person, and society" (Lewis, Jones, \& Baker, 2012, p. 642). Originally, the term referred to the deliberate pedagogical practice of switching the mode of input and output in bilingual classrooms (Lewis et al., 2012). As Creese and Blackledge (2015) noted, pedagogical translanguaging is about the normalization of bilingualism without diglossic functional separation. This normalization has been instrumental in creating space for minority and indigenous languages in classrooms.

On a global scale, English has expanded in parallel with the politics of global trade (Blommaert, 2010) - and in doing so has displaced local languages and cultures (Joseph \& Ramani, 2012). It is sometimes considered a bully or bulldozer language, forcing out or minimizing the use of indigenous and minority languages in favour of English with the promise of economic gains. Translanguaging presents a much-needed opportunity for the language practices of minority language speakers to be recognized and legitimized. Applied with care, translanguaging can help maintain, develop, and promote students' home languages for educational purposes while also facilitating the acquisition of an additional language (Joseph \& Ramani, 2012).

The selective use of written English in ASL classrooms is a deliberate pedagogical choice; however, simultaneously discouraging the use of spoken English problematizes ASL-English bilingualism by limiting modality use to only what is accessible visually. The following sections explore translanguaging for 
ASL L2 learning. We point to the unique interface of ASL and English. We hold throughout that translingual practices - whether fully or selectively - are not to be avoided, but that more research is needed to understand how they can be applied conscientiously.

\section{ASL and English tensions}

Otheguy, García, and Reid (2015) maintain that translanguaging, in its intended use, disrupts the socially constructed language hierarchies by reminding linguists that a named language is a social construct rather than a mental or psychological one. However, in ASL research, "the view of sign languages as bounded systems is often important for deaf community empowerment" (Snoddon, 2017, p. 303). While ASL is not a derivative of English, a reality of being a minority language in a predominantly English-speaking country means that ASL is in constant contact with English, and English continues to have an impact on ASL (Peterson, 2009). Delineating ASL allows researchers to position it as an equal but distinct language. Until recently, sign language linguists emphasized the arbitrary nature of ASL and downplayed elements of visual iconicity out of concern that acknowledging iconic signs would be akin to admitting that sign languages are not "real" languages (Valli, Lucas, \& Mulrooney, 2005). This attitude is telling of the skepticism around the validity of ASL in the wider linguistic community.

For these and other reasons, ASL as L2 was initially resisted by academic faculty in foreign language programs (Jacobowitz, 2005; Miller, 2008). Historically, ASL has been strongly and systematically suppressed, particularly within the realm of deaf education (Lane et al., 1996). Recent translanguaging projects have sought to reclaim ASL for deaf communities, and to show how the use of multiple modes of meaning making (signed, spoken, and written) allows deaf students to contribute more fully to classroom dialogue (Swanwick, 2017). Canagarajah (2011) described this as the valorization of a supressed community practice. For deaf education, translanguaging practices can be a means to validate and encourage the use and preservation of ASL, battle language deprivation, and encourage bilinguals to be flexible in using their linguistic resources as they make sense of their worlds (García \& Leiva, 2014).

Still, not all research finds translanguaging practices where ASL and English are concerned to be wholly positive. Some (e.g., Supalla, 2008; Supalla $\&$ Clark, 2015) question the extent to which cross-linguistic ASL-English contact should be promoted at all. Translanguaging may be viewed as a threat or a step backwards. For instance, Snoddon (2017) found that deaf ASL instructors try to support social justice for signing communities by encouraging the acquisition of classical ASL varieties. This means bringing learners' signing in line with more historically "pure" forms of ASL (i.e., by removing evidence of 
English influence). Classical ASL rejects the intrusion of English - for example, removing or altering initialized signs from ASL repertoires (e.g., FAMILY, CLASS) despite the fact that many of these signs are widely used as-is in deaf signing communities. Some signers (see, for example, Bienvenu, 2018) have pushed back against the current purification trend of removing linguistic evidence of ASL's contact with English.

In the context of ASL as L2, translanguaging practices may threaten to perpetuate existing power and status imbalances between ASL and English. The majority language, English, is in no danger; it will still be there even if some features from minority languages are inserted into it (Cenoz \& Gorter, 2017). Currently across North America ASL "abides an unsteady détente with English, an accommodation much lamented by ASL purists" (Peterson, 1999, p. 3; see also Snoddon, 2017, for a discussion of classical and variants of ASL). Thus, the implementation of strict policies (like the No Voice rule) arise. However, it stems from the desire to shelter ASL from historically problematic English influence rather than from evidence that it works as an effective teaching strategy for second-language learners.

\section{Needs of ASL L2 learners}

Translanguaging literature has yet to be extended to emerging bilingual/bimodal hearing adult learners of sign language. Additionally, ASL as a second language is not as well researched compared to other more commonly taught spoken minority languages. The needs of these learners, their proficiency attainment, and even the efficacy of particular teaching methods remain largely undocumented and uninvestigated (McKee, Rosen, \& McKee, 2014; QuintoPozos, 2011; Tanner, 2014; Willoughby, Linder, Ellis, \& Fisher, 2015). These gaps leave ASL instructors with little support for their pedagogical choices, aside from anecdotal evidence or gut feelings about their learners (Thoryk, 2010). Our current application of translanguaging theory to the pedagogical ASL practice of forbidden spoken English in the classroom is an invitation to continue examinations of ASL teaching and learning.

\section{Variety of learner profiles}

ASL L2 learners are not a homogenous group. They vary by age, previous experience with ASL or other languages, and familiarity with the deaf community. They also differ in their motivations for learning ASL: professional (e.g., to become an interpreter, audiologist, speech therapist or social worker), personal (e.g., to communicate with a deaf child or friend), pleasure (i.e., enjoyment or curiosity), or a shifting combination of these. ASL programs also vary - by setting (e.g., college, university, community program), course offerings (e.g., number of courses, levels offered), and purpose (e.g., pre-/interpretation, par- 
ents of deaf children).

The population we address in this article is hearing adults in college or university ASL L2 courses. These learners tend to be between the ages of 18-25 and have a wide range of previous experience and familiarity with ASL and the deaf community (Tanner, 2014). A few are able to fingerspell their names, and some may know a handful of signs, but in many cases the learners - particularly in introductory classes - have no experience with ASL outside of what they have seen on television or in movies (Tanner, 2014). For many learners interacting with a deaf ASL instructor is their first time ever communicating with a deaf person (Tanner, 2014).

Despite myriad differences, a common link amongst the learner population is that they are adults and have access to a first language. As Krashen (1981) showed, adult L2 learners are aware of their language learning processes. They are capable of reflecting on their learning and are able to choose from multiple strategies to intervene in or mediate their learning. It is important that research takes their feedback and preferences into account; they are stakeholders in the learning process as much as their instructors.

\section{ASL L2 acquisition}

The No Voice policy is meant to immerse students in the visual world while they are in the classroom. Teachers may also use it as a way to protect ASL from English influences or as a barrier to limit L1 transfer errors. Some instructors believe that prohibiting the use of voicing in the classroom helps students adjust to comprehending linguistic information visually rather than aurally (Peterson, 1999). Others assume that the No Voice policy will make students more likely to use gesture and that over time this will turn into signing (Calton, 2013). The idea that the use of voice presents a linguistic threat to ASL is predicated on the assumption that disallowing language use other than the target language in the language classroom leads to more fluent signers, or to signers who will then go on to present a "purer" form of ASL (i.e., ASL that exhibits fewer English intrusions) in their own signing. All of these are compelling reasons for the No Voice policy.

The problem is there is little evidence that silent classrooms actually result in hearing learners who are more comfortable, more fluent, and less prone to incorporating signed English or hybrid English-ASL forms. L2 literature outside of ASL shows that the selective use of a shared common classroom language in L2 learning contexts has already been recognized as a beneficial pedagogical practice. It enables learners to work at a higher level and have greater learning opportunities than they would be able to if they were restricted to using the L2 alone (Hussein, 2013; Storch \& Wigglesworth, 2003). Swain, Brooks, and Toccalli-Beller (2002) point out that the tasks and activities that the learners 
are engaged in will affect the dialogue learners produce and therefore the language they learn. Language activities in ASL could include translingual practices (even potentially voicing) that encourage students to understand their language use as an integrated system and that would support them as they strive to create meaning while learning.

\section{The linguistic identity of hearing $\mathrm{L} 2$ signers}

The ASL/English dichotomy (or, more generally, the spoken versus sign language dichotomy) highlights how little ownership in the language hearing learners are afforded. A common view of ASL L2 learners is one where they need to overcome deficiencies brought on by their first (spoken) language that do not effectively accommodate a second (visual) language. Part of this is due to the previously discussed tensions relating to language contact between English and ASL. Thus the logical conclusion is that spoken language needs to be put aside - even ignored - during the learning process. As discussed next, in most classroom settings the teacher is the expert; if the teacher adopts a binary orientation, that leaves very little room for a learner to establish an emerging identity as a bi-modal language user.

The establishment of identity (in this case as a second language learner with access to additional modal resources) can take place only if the identity is recognized by others (Blommaert, 2005). This would require a willingness on the part of ASL second-language teachers to acknowledge and accept that the identities of these students are not the same as members of a deaf community, but that they are something different. It also means that we need to think more carefully about the purpose of ASL programs, the goals we have for hearing learners, and the type of identity we hope they develop. Are they meant to be conduits? Bridges? Autonomous users? Or something else? ASL teachers, and ASL programs, need to clearly understand who their students are and why they are in the classroom (Peterson, 1999) before they can develop effective and engaging teaching strategies and determine the usefulness of classroom policies like the No Voice rule.

\section{Roles of ASL teachers}

Research about ASL L2 pedagogy is scarce, particularly research about ASL L2 teachers' classroom practices and use of pedagogical resources. Cooper, Reisman, and Watson (2008) point out that there are no professional journals that support sign language instruction as a discipline; however, they also note that such a journal is not yet warranted, as much of the relevant data on ASL pedagogy is neither published nor derived from empirical study. Rosen (2010) agrees that there are few, if any, empirical studies of ASL L2 pedagogies, while Quinto-Pozos (2011) similarly calls for a systematic examination of teaching 
resources and methodologies. In one such study, Thoryk (2010) undertook an examination of the effectiveness of a finger-spelling teaching resource, finding that the materials were of no help and even a hindrance in improving students' signing skills. She echoes calls for research-based sign language instructional materials.

These calls for additional research must be considered alongside Peterson's (2009) observations that the deaf community has been largely displaced as the heart of sign language interpreter training in favour of research-based and institutionalized training programs. This distancing between the language and the community is at risk of extending to other realms of research and practice, e.g., ASL as L2, to the detriment of the community. All in all, there is consensus that ASL instruction should be better supported by empirical research, but not how that can be done in a coherent, effective, and sensitive way. The handful of empirical studies that discuss ASL L2 teaching (Doré, 2014; Quinto-Pozos, 2011; Schornstein, 2005; Tanner, 2014; Thoryk, 2010) do little to explore particular classroom practices such as the No Voice policy. We maintain that while the policy may achieve cultural purposes, empirical investigation is required in order to determine whether this comes at a cost to learners' language acquisition and ability to engage in bi-modal translanguaging practices.

We approach the No Voice policy currently conceptually but with the hope that it will be examined empirically in the future. We are also interested in the rationale that teachers apply to their implementation of the rule. Is the No Voice policy a teaching moment meant to promote full visual immersion? Does it achieve the cultural purpose of creating a deaf-friendly zone? Is it a matter of linguistic respect? These questions are not easily answered, since ASL teachers are not a homogenous group. Doré (2016) found that ASL L2 teachers in Canadian post-secondary programs may have anywhere from a few years to a lifetime of experience using and teaching ASL. Further, they may be born deaf, late deafened, hard of hearing, or hearing (or anywhere in between) and may use sign language as their L1 or L2. Any proposal to study ASL L2 teaching and learning must consider this diversity.

For example, not all ASL teachers will be equally comfortable with English. If a teacher is comfortable reading, writing, lip reading, and/or speaking English, they may nonetheless recognize that not all of the deaf people that their students will encounter will be, and so students should learn to communicate without relying on the oral/aural channel. If a teacher is less comfortable with English, it is unclear how these teachers navigate English even if it is used only in the written modality as a complement to the No Voice rule. Regardless of their English proficiency, deaf teachers may find that restricting the spoken modality creates a more equal playing field between them and their hearing stu- 
dent, where classroom management and student progress become more easily monitored. This scenario is quite different from spoken language teachers, who are likely to be bilingual and share a comfort with the same modalities (spoken and written) as the students. These teachers may be more amenable to students accessing their wider repertoire of language skills - i.e., in both spoken and written modalities - since they can access students' learning through these.

The following sections explore several specific ways that the No Voice policy as selective modality translanguaging pedagogy meets and conflicts with ASL L2 teachers' needs. Of course, this compartmentalization is somewhat artificial, as teacher needs overlap to varying extents with students' needs and considerations regarding ASL as a minority language.

\section{Teachers as gateways}

ASL L2 teachers have been conceptualized as "gateways" to the deaf community (Kelly, 2001). As such, ASL teachers have more specific cultural goals than spoken language teachers. Calton (2013) observed that ASL L2 teachers place less emphasis on language proficiency and more emphasis on exposing new learners to the history and culture of the deaf community and imparting on their students a respect for deaf people and ASL. Thus, ASL L2 teachers may see themselves as responsible for exposing hearing learners to the history and culture of the deaf community and creating "good citizens within the deaf community" (McDermid, 2009, p. 108). These goals are manifested in different approaches to teaching that, as a whole, take on many of the aspects that are important to deaf culture and socialization such as reciprocity, collectivism, and enculturation into deaf communication norms (McDermid, 2009). These approaches aim to "engender an appreciation of deaf culture and respect for ASL and the Deaf" in their students (Calton, 2013) in the hope that their students "adopt a socio-cultural model of Deafness" (p. 93) over the course of the class. The No Voice policy is one more way that this is accomplished. This may, however, have the effect of prioritizing learners' cultural awareness ahead of linguistic proficiency.

\section{Teachers as spokespeople}

In discussing any aspect of teaching ASL one must always take into account the history of ASL instruction (both as a first and second language) over the years. Anything related to ASL pedagogy, whether it be strictly linguistic or a matter of broader classroom practices such as translanguaging, "is superposed on the socio-cultural history of the Deaf community" (Quinto-Pozos, 2011, p. 138). The displacement of Indigenous languages in favour of English has meant that historically the use of ASL by deaf signers was seen as shameful, uneducated, or backwards. The history of ASL across North America includes 
a long history of oppression leading to a set of exigent and complex dynamics that include power differentials between deaf and hearing, as well as issues of social capital and definitions of disability. Thus, the No Voice policy may be an important way of embedding in the pedagogy a reminder of the historical and ongoing oppression of sign languages and of learners' hearing privilege. Teachers, as the primary classroom experts in sign language and deaf history and culture, take on the role of spokespeople responsible for guiding students and positioning them in relation to it.

\section{Teachers as experts}

ASL teaching was and continues to be a significant career opportunity for deaf people (McKee, Rosen, \& McKee, 2014). As suggested in the previous section about ASL as a minority language, ASL as L2 is tied to questions of language ownership. The deaf native signer is often positioned as the knowledge expert on the language and culture, though they are few and far between. This is because $90 \%$ of deaf children are born to hearing parents (Meier, 1991; Mitchell \& Karchmer, 2004) and come to sign language and the deaf community at school age or later in life, if at all. Consequently, ASL teachers have varying experiences with ASL in addition to different knowledge of language pedagogy and linguistics (Cooper, Reisman, \& Watson, 2008). Rosen (2010) argues that the inconsistencies amongst ASL curricula and curricula adoption raises questions about teachers' understanding of second-language acquisition principles, curriculum development, and instructional strategies. Moreover, a significant proportion of the signing community is hearing - children of deaf adults, interpreters, parents and teachers of deaf children, spouses, friends, and colleagues of deaf people, and so on - many of whom are fluent signers themselves, which complicates the deaf signer as the primary and/or sole expert. While a strong argument can be made for the No Voice policy on cultural, social, and political grounds, it is less clear how the policy is meant to improve second language learning. In a language classroom of hearing learners there should be a strong empirical rationale for the complete ban on a communicative modality.

In sum, we hold that teachers (and programs in particular) should consider their goals: are teachers expected to prioritize linguistic proficiency (e.g., for interpreter training) or cultural knowledge (e.g., for socializing with deaf communities)? Should they teach around their own preferred modalities - whether spoken, written, or signed, or some combination of two or three - or should pedagogies be more standardized to accommodate a range of teachers? 


\section{Conclusion}

Classroom contexts and norms significantly influence learners' willingness and ability to participate. Tyler (2012) suggests that shifting the focus away from traditional teacher-oriented classrooms to learner cooperative/collaborative classrooms may increase the level of interpersonal trust, which can be an antecedent to willingness to communicate in the second language. Adults also tend to prefer more self-directed and student-centred approaches (Tudor, 1996). Translanguaging in an ASL classroom that allows students to voice requires teachers who are co-learners and who are willing to build a classroom where students are allowed "to write and speak with whatever resources they have and not wait until they have the "legitimate' ones to develop a voice" (García, 2016, para. 5).

Given the swift rise in the number of ASL programs that instruct hearing learners, the lack of research into the ways in which ASL is taught and learned is a pressing concern. Currently, much of ASL teaching is informed by the linguistic and cultural beliefs of instructors (Quinto-Pozos, 2011). We agree that there is a need to maintain and protect minority languages like ASL. It is also important that language classrooms address cultural issues and encourage understanding of, and sensitivity to, cultural difference. However, we also suggest that the development of materials and pedagogical approaches used to teach hearing L2 learners should be genuinely useful rather than merely popular (Thoryk, 2010) or chosen based on existing precedence; the No Voice rule has strong cultural sway but its relevance as a teaching tool needs closer examination.

While increased mainstream acknowledgement of the existence of sign languages may be leading to slowly straightening misconceptions around its nature (“Aren't sign languages universal?"), discriminatory ideas around the primary cultural group associated with sign languages - deaf people - are holding strong ("Can't they all lip read?"). A linguistic paradigm shift, i.e., embracing the unique contributions of sign languages to linguistic diversity, seems to be easier to swallow than a social one, i.e., recognizing the unique contributions of deaf people to the hearing-dominant social tapestry. Consequently, the growth of ASL in North America is experiencing ethical and moral growing pains, where increased language recognition and growth is checked by questions of language ownership and language shift through the increased contact between ASL and English. Meanwhile, technologies like cochlear implants are spreading and fundamentally altering deaf culture and communities at the same time as digital communication, recording, and dissemination technologies (e.g., video chat, Video Relay Service [VRS], video- and image-based social media) are connecting sign language users faster than ever. Thus, it is of the utmost importance that deaf teachers and other members of signing com- 
munities are empowered in matters that concern them. But discussions of ASL L2 instruction need to also consider the linguistic and learning needs of hearing L2 students.

For learners, selective use of voicing (for example, in peer to peer interaction) may be an asset rather than something that diminishes ASL learning. The point is to expand on students' existing knowledge (linguistic, metalinguistic, social, cultural) and help them develop shared linguistic and cultural understandings and language practice repertoires (Alamillo, Yun, \& Bennett, 2017). Depending on the learners' ASL level and the goals of the course, it may be appropriate in some cases to allow the use of voicing for teaching and/or discussion of (for example) metalinguistic skills. One consideration for ASL teachers would be to include learning activities that allow for interaction in a way that uses English or voice to support and mediate second language learning. This need not be an everyday occurrence - even small amounts of this type of scaffolding can lead to language learning gains. Peer to peer interactional translingual practices can help build interpersonal trust among adults as co-learners.

We want to be clear that we do not disagree with the desire to protect and preserve ASL, and we believe that students should learn experientially about deaf culture. We are calling for more research that looks at the needs of all stakeholders, while making sure that ASL L2 research (and by extension, ASL L2 instructors) consider the value that theoretical developments like translanguaging can contribute to hearing learners' understanding and linguistic development.

\section{References}

Alamillo, L., Yun, C., \& Bennett, L.H. (2017). Translanguaging in a Reggio-inspired Spanish dual-language immersion programme. Early Childhood Development and Care, 187, 469-486.

Bienvenu, M.J. (2018, Jan 18). Purification of ASL, no! [Video file]. www.youtube.com/ watch?v=2zXhE5gv3Pw

Blommaert, J. (2005). Discourse: A critical introduction. Cambridge: Cambridge University Press.

Blommaert, J. (2010). The sociolinguistics of globalization. Cambridge: Cambridge University Press.

Calton, C.J. (2013). Teaching respect: Language, identity, and ideology in American Sign Language classes in the United States (Doctoral dissertation). ir.uiowa.edu/etd/ 4950

Canagarajah, S. (2011). Translanguaging in the classroom: Emerging issues for research and pedagogy. Applied Linguistics Review, 2 (1-27). 
Cenoz, J., \& Gorter, D. (2017). Minority languages and sustainable translanguaging: Threat or opportunity? Journal of Multilingual and Multicultural Development, 38, 901-902.

Chomsky, N. (1976). On the nature of language. Annals of the New York Academy of Sciences, 280, 46-57.

Cooper, S.B., Reisman, J.I., \& Watson, D. (2008). The status of sign language instruction in institutions of higher education: 1994-2004. American Annals of the Deaf, 153, 78-88. doi.org/10.1353/aad.0.0001

Creese, A., \& Blackledge, A. (2015). Translanguaging and identity in educational settings. Annual Review of Applied Linguistics, 35, 20-35.

de Saussaure, F. (2017). "Cours”. In M. Ryan \& J. Rivkin (Eds.), Literary theory: An anthology (3rd ed., pp. 137-177). Malden, MA: Blackwell.

Doré, C. (2014). Exploring teacher perceptions of a textbook-free ASL curriculum at a Canadian university: A qualitative combined methods study. (Unpublished doctoral dissertation). Carleton University, Ottawa.

Doré. C. (2016). Assessing the needs of ASL teachers in Canada. Unpublished manuscript. Carleton University, Ottawa.

García, O. (2009). Education, multilingualism and translanguaging in the 21st century. In A. Mohanty, M. Panda, R. Phillipson, \& T. Skutnabb-Kangas (Eds.), Social justice through multilingual education (pp. 128-145). New Delhi: Orient Blackswan.

García, O. (2016, March). What is translanguaging? An interview with Ofelia García. (F. Grosjean, Interviewer). Psychology Today. www.psychologytoday.com/us/blog/ life-bilingual/201603/what-is-translanguaging

García, O., \& Leiva, C. (2014). Theorizing and enacting translanguaging for social justice. In A. Blackledge \& A. Creese (Eds.), Heteroglossia as practice and pedagogy (pp. 199-216). New York: Springer.

García, O., \& Wei, L. (2014). Translanguaging: Language, bilingualism, and education. New York: Palgrave MacMillan.

Goldberg, D., Looney, D., \& Lusin, N. (2015). Enrollments in languages other than English in United States institutions of higher education, Fall 2013. New York: Modern Language Association (MLA). apps.mla.org/pdf/2013_enrollment_survey.pdf

Hussein, B. (2013). Teaching and learning English-as-a-second/foreign language through mother tongue: A field study. Asian Social Science, 9(10), 175-180.

Jacobowitz, E.L. (2005). American sign language teacher preparation programs in the United States. Sign Language Studies, 6, 76-110.

Joseph, M., \& Ramani, E. (2012). Glocalization: Going beyond the dichotomy of global versus local through additive multilingualism. International Multilingual Research Journal, 6, 22-34. 
Kelly, A.B. (2001). How Deaf women construct teaching, language, and culture, and gender: An ethnographic study of ASL teachers (Unpublished doctoral dissertation). University of Maryland, College Park, MD.

Krashen, S.D. (1981). Second language acquisition and second language learning. New York: Pergamon Press.

Komesaroff, L.R. (2008). Disabling pedagogy: Power, politics, and deaf education. Washington, DC: Gallaudet University Press.

Kuntze, M., Golos, D., Wolbers, K., O’Brien, C., \& Smith, D. (2016). School as a site for natural language learning. In M. Marschark, V. Lampropoulou, \& E.K. Skodilis (Eds.), Diversity in deaf education (pp. 77-108). New York: Oxford University Press.

Lane, H.L., Hoffmeister, R., \& Bahan, B.J. (1996). A journey into the deaf-world. San Diego, CA: Dawnsign Press.

Lewis, G., Jones, B., \& Baker, C. (2012). Translanguaging: Origins and development from school to street and beyond. Educational Research and Evaluation, 18, 641654.

McDermid, C. (2009). Social construction of American Sign Language - English interpreters. Journal of Deaf Studies and Deaf Education, 14, 105-130.

McKee, R.L., \& McKee, D. (1992). What's so hard about learning ASL?: Students' and teachers' perceptions. Sign Language Studies, 75, 129-158.

McKee, D., Rosen, R., \& McKee, R. (2014). Introduction. In D. McKee, R. Rosen, \& R. McKee (Eds.), Teaching and learning signed languages: International perspectives and practices (pp. 1-7). New York: Palgrave MacMillan.

Meier, R.P. (1991). Language acquisition by deaf children. American Scientist, 79, 6070.

Miller, K.R. (2008). American Sign Language: Acceptance at the university level. Language, Culture and Curriculum, 21, 226-234.

Mitchell, R.E., \& Karchmer, M. (2004). Chasing the mythical ten percent: Parental hearing status of deaf and hard of hearing students in the United States. Sign Language Studies, 4, 138-163.

Otheguy, R., García, O., \& Reid, W. (2015). Clarifying translanguaging and deconstructing named languages: A perspective from linguistics. Applied Linguistics Review, 6, 281-307. doi.org/10.1515/applirev-2015-0014

Peterson, R. (1999). The perceptions of deafness and language learning of incoming ASL students (Unpublished doctoral dissertation). University of California Riverside.

Peterson, R. (2009). The unlearning curve: Learning to learn American Sign Language. Burtonsville, MD: Sign Media Inc.

Quinto-Pozos, D. (2011). Teaching American Sign Language to hearing adult learners. Annual Review of Applied Linguistics, 31, 137-158. 
Rosen, R. (2010). American Sign Language in US high schools: State of the art. Modern Language Journal, 92, 10-38.

Schornstein, R.A. (2005). Teaching ASL in the university: One teacher's journey. Sign Language Studies, 5, 398-414. (2006). doi.org/10.1353/sls.2005.0019

Snoddon, K. (2008). American Sign Language and early intervention. Canadian Modern Language Review, 64, 581-604.

Snoddon, K. (2017). Uncovering translingual practices in teaching parents classical ASL varieties. International Journal of Multilingualism, 14, 303-316.

Storch, N., \& Wigglesworth, G. (2003). Is there a role for the use of the L1 in an L2 setting? TESOL Quarterly, 37, 760-770.

Supalla, T. (2008). Sign language archeology: Integrating historical linguistics with fieldwork on young sign languages. In R.M. de Quadros (Ed.), Sign languages: Spinning and unraveling the past, present and future. Proceedings of the Ninth International Conference on Theoretical Issues in Sign Language Research (TISLR9) (pp. 575-583). Petropolis, Brazil: Editora Arara Azul.

Supalla, T., \& Clark, P. (2015). Sign language archaeology: Understanding the historical roots of American Sign Language. Washington, DC: Gallaudet University Press.

Swain, M., Brooks, L., \& Tocalli-Beller, A. (2002). Peer-peer dialogue as a means of second language learning. Annual Review of Applied Linguistics, 22, 171-185.

Swanwick, R. (2017). Translanguaging, learning and teaching in deaf education. International Journal of Multilingualism, 14, 233-249.

Tanner, J. (2014). Examining the construct of proficiency in a university's American Sign Language (ASL) program: A mixed-methods study (Unpublished doctoral dissertation). Carleton University, Ottawa.

Tevenal, S., \& Villanueva, M. (2009). Are you getting the message? The effects of SimCom on the message received by deaf, hard of hearing, and hearing students. Sign Language Studies, 9, 266-286.

Thoryk, R. (2010). A call for improvement: The need for research-based materials in American Sign Language education. Sign Language Studies, 11, 100-120.

Tudor, I. (1996). Learner-centeredness as language education. Cambridge, MA: Cambridge University Press.

Tyler, R.qJ. (2012). Interpersonal trust and willingness to communicate in the adult foreign language classroom. Dialog on Language Instruction, 22, 1-21.

Valli, C., Lucas, C., \& Mulrooney, K. (2005). The linguistics of American sign language: An introduction (4th ed.). Washington, DC: Gallaudet University Press.

Willoughby, L., Linder, S., Ellis, K., \& Fisher, J. (2015). Errors and feedback in the beginner Auslan classroom. Sign Language Studies, 15, 322-347. 